\title{
Monmouth dentist plans gruelling run for prostate cancer
}

On 9 April 2021 Gareth Jones, the 'Triathlete Dentist,' will attempt to run up the Kymin, a big hill which overlooks his hometown of Monmouth, 37 times. This is the equivalent of climbing Mount Everest (8,848 m).

On his blog, Gareth, who works at Monmouth Dental Practice in South Wales, writes that 'Everesting' has been completed by 6,900 cyclists but only 322 runners (as of 21 December). The runner must use the same route and not sleep during the repetitions. It is acceptable to either cycle or get a lift back down the hill only running the uphill sections.

Through undertaking the challenge, Gareth is hoping to raise $£ 5,000$ for Prostate Cancer UK. One in eight men is diagnosed with prostate cancer in their lifetime and Gareth's dad is currently fighting the disease.

For more information visit https:// triathletedentist.wordpress.com/2020/12/21/ everest-wales-the-biggest-challenge-yet.

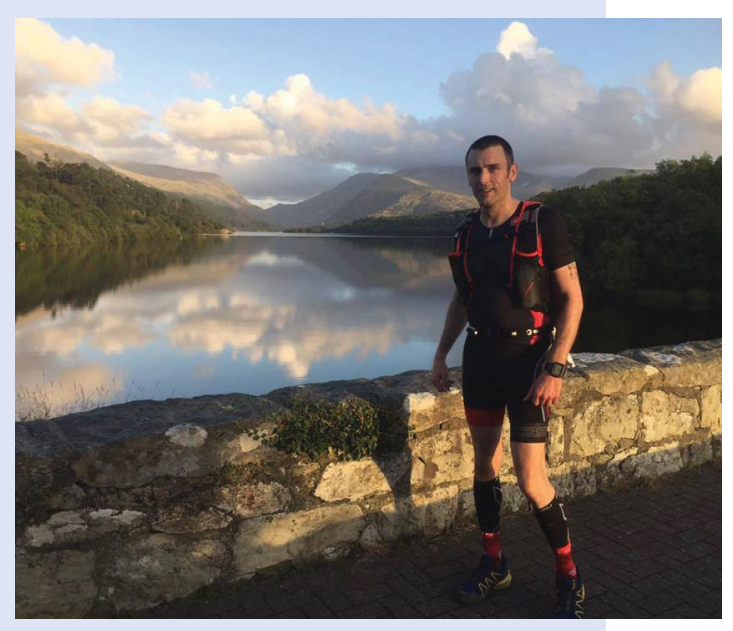

\section{First-of-its-kind MS in Minimally-Invasive Aesthetics set for September}

By Professor Ash Mosahebi, UCL Division of Surgery and Interventional Science

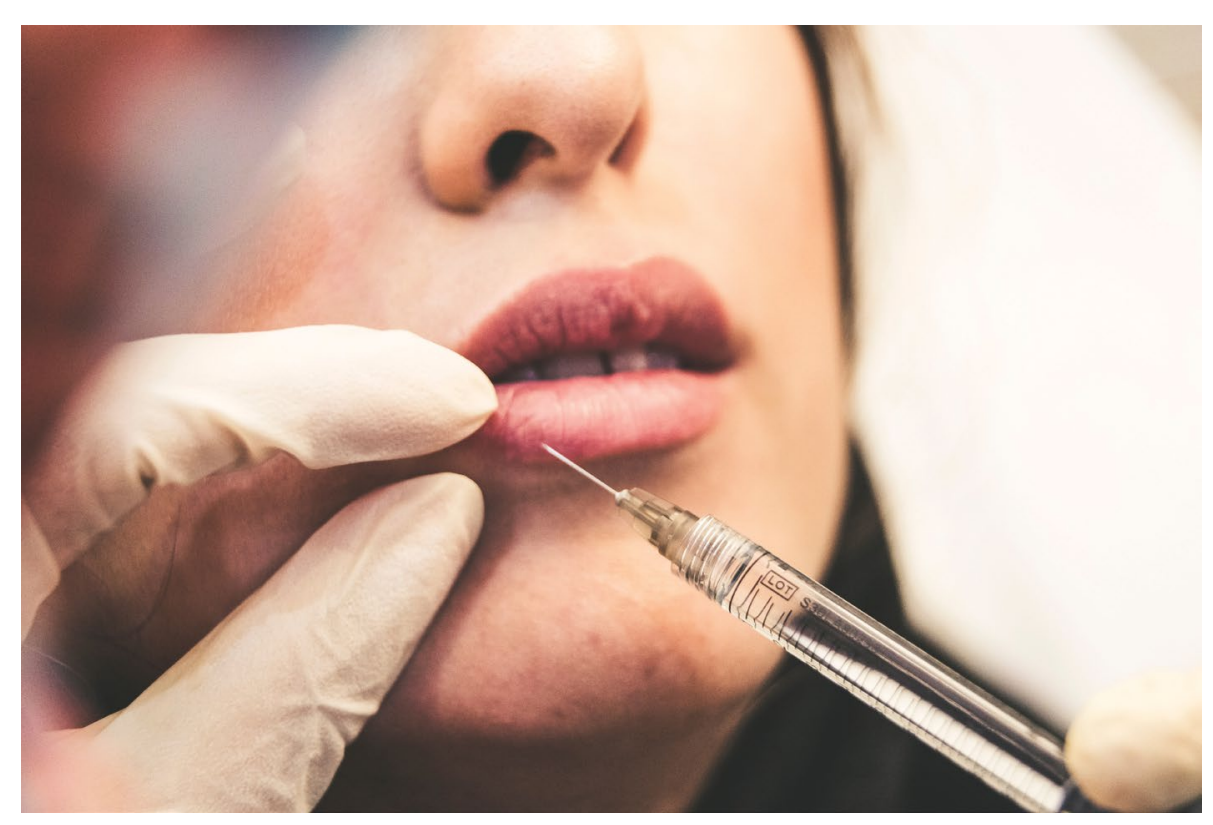

Photo credit: Upsplash Sam Moqadam

Lack of regulation and training in cosmetic surgery has been an issue for years, and as the popularity of cosmetic treatments increases, the problem has been gathering pace.

UCL steps up this September 2021 with its Masters in Surgery (MS) for aesthetics treatments, of which I am proud to be leading with the international faculty. We will welcome our first cohort of students in the autumn, which will include dentists.

This will make UCL the first-ever global academic institution to offer a comprehensive
Masters of Surgery (rather than a Masters of Science) in Aesthetics Surgery and Minimally-Invasive Aesthetics.

In 2015, Sir Bruce Keogh's recommendation was that the government's mandate for Health Education England (HEE) should include the development of accredited postgraduate qualifications for providers of non-surgical interventions and that it should determine accreditation requirements.

As this sector is outside the NHS, its governance has been the focus of much debate over recent years. Current regulations place no restrictions on who performs nonsurgical cosmetic procedures. The British Association of Aesthetic Plastic Surgeons (BAAPS) supports the UCL Masters which helps to improve aesthetics training standards. BAAPS' research strategy will help form the research element of our Masters and direct future improvements and safety practices.

UCL is still taking applications for its two MS courses:

1. MS Aesthetics (Minimally-Invasive Aesthetics) will include principles and practice of aesthetics and research context, epigenetics and regenerative aesthetics, fundamentals of minimallyinvasive facial aesthetics, minimallyinvasive aesthetic practice and advanced minimally-invasive aesthetic practice Applicants should have medical or dental (BDS) or be an advanced nurse practitioner registered with NMC, or a prescribing pharmacist registered with GPh

Discover more/apply here: https://www.ucl.ac.uk/prospectivestudents/graduate/taught-degrees/ minimally-invasive-aesthetics-ms

\section{MS Aesthetics (Aesthetic Surgery) is} designed for surgeons

Discover more/apply here: https://www. ucl.ac.uk/prospective-students/graduate/ taught-degrees/aesthetic-surgery-ms. 